\title{
Kollisionsrechtliche Probleme der Telemedizin
}

Zugleich ein Beitrag zur Koordination von Vertrag und Delikt auf der Ebene des europäischen Kollisionsrechts

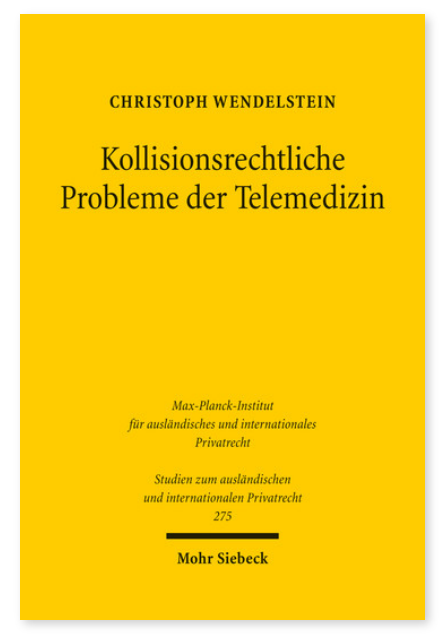

2012. XXXII, 541 Seiten. StudIPR 275

ISBN 978-3-16-152192-8

DOI 10.1628/978-3-16-152192-8

eBook PDF $114,00 €$

ISBN 978-3-16-152011-2

fadengeheftete Broschur 114,00€
Während herkömmliche Behandlungsformen nur geringfügigen Spielraum für kollisionsrechtlich relevante Auslandsbeziehungen lassen, ist dies bei der Telemedizin im Hinblick auf die technische Möglichkeit, weite Distanzen zwischen Arzt und Patient zu überbrücken, grundsätzlich anders. Damit eröffnet die Telemedizin für das Arzthaftungsrecht eine breite Palette neuer Probleme des internationalen Privat- und Verfahrensrechts. Christoph Wendelstein widmet sich diesen Problemen und stellt dabei das Kollisionsrecht ins Zentrum seiner Untersuchung. Insgesamt verfolgt er bei alledem zwei Zielrichtungen: Einerseits wird für alle wichtigeren Rechtsfragen, die im Zusammenhang mit telemedizinischen Behandlungen auftreten können, die kollisionsrechtliche Problematik im Einzelnen erörtert. Daneben geht es dem Verfasser jedoch um mehr: Er will anhand des internationalen Arzthaftungsrechts das Verhältnis von Vertrags- und Deliktsstatut grundsätzlich neu überdenken und damit einen »Beitrag zur Koordination von Vertrag und Delikt auf der Ebene des europäischen Kollisionsrechts« leisten.

Christoph Wendelstein Geboren 1982; Studium der Rechtswissenschaften an den Universitäten Tübingen und Passau; 2012 Promotion; 2010-12 Rechtsreferendar am LG Stuttgart; 2011-12 wissenschaftlicher Mitarbeiter an der juristischen Fakultät der Universität Tübingen; Akademischer Rat a.Z. an der Universität Konstanz. https://orcid.org/0000-0001-8653-8386

Jetzt bestellen:

https://mohrsiebeck.com/buch/kollisionsrechtliche-probleme-der-telemedizin-9783161521928?no_cache=1 order@mohrsiebeck.com

Telefon: +49 (0)7071-923-17

Telefax: +49(0)7071-51104 